\title{
TESTING, DETERMINATION AND VALIDATION OF THE MATHEMATICAL EQUATION AN ANTIMONY PH SENSOR
}

\author{
DOBOCAN, C[orina] A[driana]; STOICA, O[ctavian]; POPESCU, D[aniela] \& TOPA, V[asile]
}

\begin{abstract}
This paper presents testing mode, determinating and validating the mathematical equation an antimony $p H$ sensor. The introduction offers an incursion on the mine water and a definition of the pH concept, a brief history of it and continues with a short presentation of the elements which can make a possible variant of $\mathrm{pH}$ measurement, more precise the variant which use $\mathrm{pH}$ electrode/pH sensor. In the content of the paper is exposed a theoretical synthesis of the way of testing and validation of $\mathrm{pH}$ electrodes $/ \mathrm{pH}$ sensors, which makes the transition to the actual testing of the studied $\mathrm{pH}$ sensor. The elements used for test and also the sensor response are viewed in photographs and graphics, which helps the reader to understand the practical part. Further, in paper, are presented short theoretical considerations followed by the dependence of electrical potential sensor analysis in relation with the change in $p H$ solutions in which it was immersed. Conclusively, the most important conclusions are accentuated after the analysis, continued with some future research directions. Conclusions highlight the paper presented results, results that are seen as an opportunity for future studies.

Keywords: determination of $\mathrm{pH}, \mathrm{pH}$ electrode, test sensors, antimony, unifactorial linear regression, analysis
\end{abstract}

\section{INTRODUCTION}

Mine water is meteoric water or groundwater composition undergoes changes due to interactions with mineral components of the deposit that you wash. Mine water is formed by mixing natural water from precipitation seeps into the mining and water network technology introduced in the process. Natural water seeps into the pores and cracks mine rocks by faults deposit or older works that are flooded, ruins, etc. drainage construction.

Work in quarries and underground mines expand, usually below the phreatic water layer and require controlled disposal of water that accumulates during mining operations.

Water flow is generally reduced if mining eruptive and metamorphic rocks excavated, and high or very high in the dug in sedimentary rocks, especially when they are unconsolidated, such as sand and gravel that are below Hydrostatic level.

In the mining water is needed to reduce dust in wet rock drilling operation for cooling compressors and other machinery, mineral processing, coal washing and hydrometallurgical extraction. For these applications, water is pumped from the surface water bodies and aquifers.
Streams that drain a surface mining area changes its composition by: quality and quantity of groundwater, storm water and waste water discharged into them. Sources of pollution of rivers where mining liquid waste waters are the results of extraction and processing the ore. Uncontrolled dumping, flow, drainage or untreated mine water infiltration into the environment causes the release of heat, suspended solids and dissolved chemicals, metals, metalloids, radioactive substances and salts.

Groundwater has a constant temperature of about 8 to $10^{\circ} \mathrm{C}$, at a depth of 10 to $30 \mathrm{~m}$ should be kept in mind that underground mining usually reach depths exceeding $1000 \mathrm{~m}$ at these depths a factor in determining water temperature mine is geothermal gradient, increasing its value to depth of $1^{\circ} \mathrm{C}$ every $33 \mathrm{~m}$.

The $\mathrm{pH}$ concept was introduced by Sorensen in 1909 as pondus hydorgenii, hydrogen exponent that become familiar to all chemists and biochemists specialists.

It is called the exponent of hydronium ion concentration or $\mathrm{pH}$, logarithm with opposite sign of hydronium ion concentration from solution:

$$
\mathrm{pH}=-\lg \mathrm{c}_{\mathrm{H}+}=\lg 1 / \mathrm{c}_{\mathrm{H}+}
$$

Later, when the thermodynamic significance of the notion of activity was better understood, the above definition was amended as follows:

$$
\mathrm{pH}=-\lg \mathrm{a}_{\mathrm{H}+}
$$

For diluted solutions, activities (a) are practically equal with concentrations (c). Therefore equation (1.1) is used more frequently, even if equation (1.2) is better founded theoretically.(reference [1])

Because a wide range of biological and chemical processes depend on $\mathrm{pH}$, its measurement is one of the most common measurements made in laboratories.

Along with the introduction of the $\mathrm{pH}$ concept appeared and its measurements methods, therefore have appeared the glass electrodes, antimony electrodes, quinhydrone electrodes, etc. used for $\mathrm{pH}$ measurement.

In process of time for easing the performing measurements, on the market appeared the combined $\mathrm{pH}$ electrode (its schematic presentation can be found in reference [2]), having as constructional elements indicator and reference electrodes. 
As described in reference [3] and presented below, a sensor is defined as a device that receives a stimulus and responds with an electrical signal. The stimulus is the quantity, property, or condition that is sensed and converted into electrical signal.

A sensor is a translator of a generally nonelectrical value into an electrical value. Hereunder when talking about electrical values, means a signal that can be channeled, amplified and modified by electronic devices. Therefore, the combined electrode can be named sensors, because in the same time with his immersion in aqueous solutions responds with an electrical signal.

\section{THEORETICAL CONSIDERATIONS ON TESTING AND VALIDATION OF THE PH ELECTRODES/PH SENSORS}

In reference [4], the antimony electrode performance on the $\mathrm{pH}$ sensitivity was evaluated by measuring the open circuit potential (OCP) in pair with a commercial reference electrode $\mathrm{Ag} / \mathrm{AgCl}$ saturated, in aqueous solutions buffers. OCP can be measured by a laboratory $\mathrm{pH} / \mathrm{mV}$-meter or a digital multimeter with a data acquisition device connected to a computer.

In order to observe the calibration curve of tested electrodes, it has been made an acid-base titration for changing the $\mathrm{pH}$ in the test solution. A multi-ion universal buffer solution with the composition of $0,01 \mathrm{M}$ $\mathrm{H} 3 \mathrm{PO} 4-\mathrm{H} 3 \mathrm{BO} 3-\mathrm{CH} 3 \mathrm{COOH}$ and $0,1 \mathrm{M} \mathrm{KCl}$ was prepared as the base solution, its initial $\mathrm{pH}$ was about 2 .

After both the $\mathrm{Sb} / \mathrm{SbOx}$ electrode and the $\mathrm{Ag} / \mathrm{AgCl}$ reference electrode were immersed into the test buffer solution and the OCP reading became sTab., 0.1 M KOH solution was added step by step and the electrode potential difference would change correspondingly.

The solution was stirred magnetically throughout the measurement and a previously calibrated glass $\mathrm{pH}$ electrode was used to monitor $\mathrm{pH}$ of the solution at the same time.

Sometimes two or more electrodes sharing a same $\mathrm{Ag} / \mathrm{AgCl}$ reference electrode were inserted into the test solution together for the measurement, to check the reproducibility for the fabrication of the electrodes.

\section{TESTING OF ANTIMONY PH SENSOR}

In the case of the antimony sensor (whose construction is presented in the document [5]), for testing it under the similar conditions to its application environments, it has been used approximately the same procedure described in reference [4] and presented previously in a synthesized manner. As we can see in Fig. 1, the elements used for performing measurements are: the heated magnetic stirrer, $\mathrm{pH}$ - meter, a temperature probe, $\mathrm{pH}$ glass sensor and of course, the antimony sensor. Exception to those presented in the theoretical considerations, is that the measurements was prepared a mixture of phosphoric acid, acetic and boric with concentration of $0.04 \mathrm{M}$ each, and for obtaining the buffer solution with desired $\mathrm{pH}$ value was added at 100 $\mathrm{ml}$ of mixture solution, $\mathrm{X}-\mathrm{ml}$ of a $0,2 \mathrm{n} \mathrm{NaOH}$. [6]

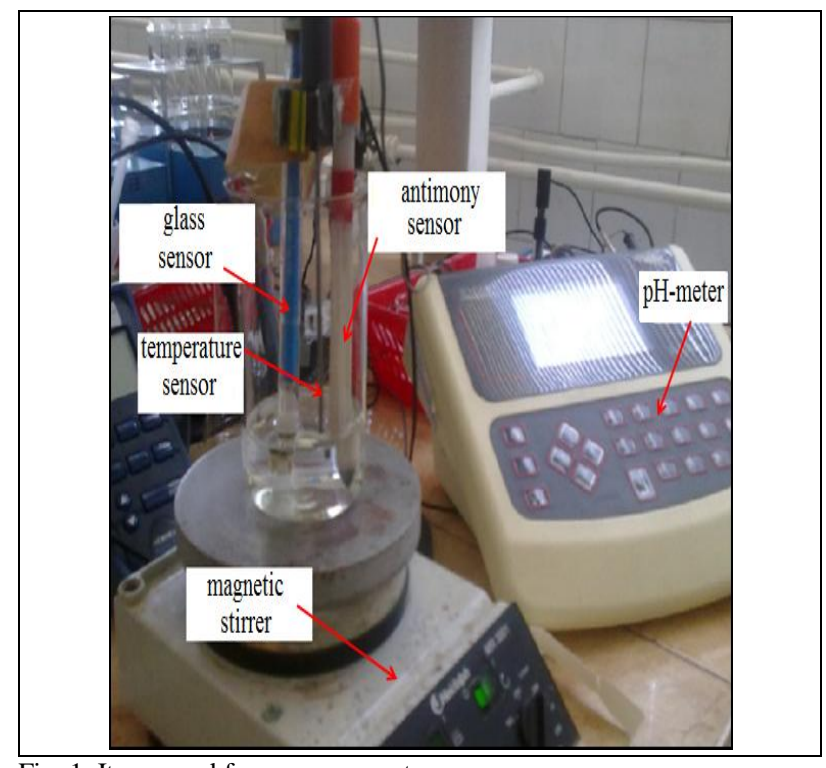

Fig. 1. Items used for measurement process

The sensitive performances of the antimony sensor, determined according with the above presentation occurs in a graphical form in Fig. 2. We can affirm that in the range of $\mathrm{pH} 2-10$, the sensor has a fast and sTab. response to $\mathrm{pH}$ changes in aqueous solutions. Its potential has a linear relation with the $\mathrm{pH}$ of solutions (coefficient of determination $\mathrm{R}^{2}=0.9997$ ) and a slope of $50.95 \mathrm{mV} / \mathrm{pH}$. Sensor response time was between 7 and 25 seconds, being determined empirically.

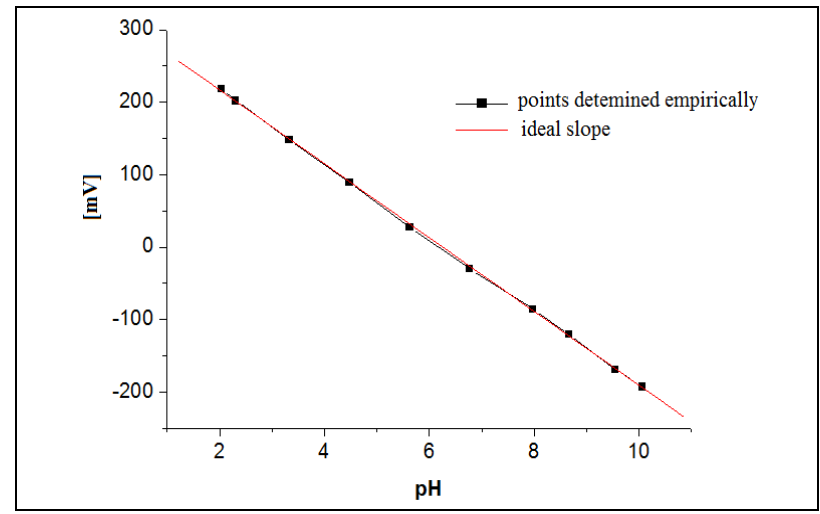

Fig. 2 Response of antimony sensor on $\mathrm{pH}$ range 2 to 10

In case of soil monitoring has sought an alternative to glass sensor, due to its membrane fragility. So, we focused our attention on metal / metal-oxide electrodes, and more precisely, on the antimony $\mathrm{pH}$ electrodes. The choice of this type of electrode was not random, being grateful to a relatively large number of scientific papers , reference [8] etc., that presents the antimony electrodes as one of the best alternative for monitoring the $\mathrm{pH}$ of soils. Therefore, after a study on the existent literature in this domain, it was developed a sensor adapted to laboratory monitoring of soils, whose construction is shown in reference [11]. The measurements made with the sensor, and the measurements made with other types of sensors, are based on the relation between electric potential response resulted after their immersion in buffer solutions with different $\mathrm{pH}$ value $(\mathrm{pH}$ buffer solutions ranging between 2 - 10). 


\section{THEORETICAL CONSIDERATIONS REGARDING THE CONNECTION BETWEEN RESPONSE ELECTRIC POTENTIAL OF SENSOR AND THE BUFFER SOLUTIONS}

The first issue which must be resolved in the analysis of connection between a dependent variable (the result, effect, explained, denoted by Y) and one or more independent variables (factorial, causal, explanatory, denoted by $\mathrm{X}_{\mathrm{i}}$ ) refers to the question: is there a connection between variable, or changing the effectvariable is influenced by causal-variable (variables) changes? For answering at this question requires to start from theory and respectively from specialized science which studying these phenomena and from empirical data recorded for the variables assumed to be correlated. Through regression method it can be analyzed through an analytical expression, called regression function, the manner of behaving the dependent variable $\mathrm{Y}$ in relation to the modification of one or more independent variables $\left(\mathrm{X}_{\mathrm{i}}\right)$.

Regression function expresses, in average the behaving of effect-variable, under influence of one or more effect-variables, in conditions where all other causal-variables, essential or accidental, would exert a constant action or would exert a non-essential influence.

Regression function is a mathematical function that expresses the relation between variables and has the general form:

$$
Y_{x i}=f\left(x_{1}, x_{2}, \ldots x_{k}\right)+e
$$

where "e" is the random disturbance variable or error value, that summarizes all factors not taken into account, unspecified.

If the regression involves one independent variable, it will be applied the linear or non-linear regression, and if the dependence of variable $\mathrm{Y}$ will acyclizate in function by at least two factorial variables, it will be applies the multifactorial regression.

Choosing the regression function can be a simple thing, based on graphical representation of pairs of values $\mathrm{x}_{\mathrm{i}} \mathrm{y}_{\mathrm{i}}$ (reference [7]).

\section{DEPENDENCE OF ELECTRICAL POTENTIAL SENSOR ANALYSIS IN RELATION WITH THE CHANGE OF SOLUTIONS PH IN WHICH IT WAS IMMERSED}

Currently there is a wide range of commercial software on market, using the statistical calculus, exemplifying : EXCEL, MATLAB, STATISTICA, MINITAB, DESIGN EXPERT, etc. The link between potential response of the built sensor (voltage supplied to it), E, and the solutions $\mathrm{pH}$ that has been immersed for the measurements, $\mathrm{pH}$, can be written in a general mathematical form as:

$$
\mathrm{E}=\mathrm{f}(\mathrm{pH})
$$

To establish this relation were taken into account the results of testing the sensor in buffer solutions that were obtained as follows:

It was prepared a mixture of phosphoric acid, acetic and boric with concentration of $0.04 \mathrm{M}$ each, and for obtaining the buffer solution with desired $\mathrm{pH}$, was added to $100 \mathrm{ml}$ mixture, $\mathrm{X}-\mathrm{ml}$ indicated by $0.2 \mathrm{n} \mathrm{NaOH}$. Therefore, the graphical representation of the solutions $\mathrm{pH}$ and the potential responses of the sensor made is presented in Fig. 3.

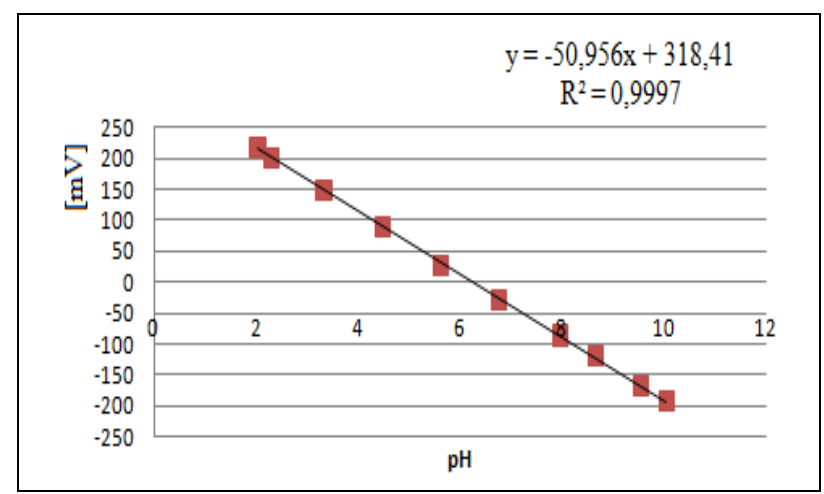

Fig. 3. The graphical representation of the solutions $\mathrm{pH}$ and the potential responses of the sensor

Introducing the Excel data obtained from the test of the sensor and again appealing to the specialized computer package, wherefrom, after selecting the main menu options <Tools $>+<$ Data Analysis $>+$ $<$ Regression $>$, it will obtain these results, see Tab. 1. :

\section{SUMMARY OUTPUT}

\begin{tabular}{l|r}
\hline \multicolumn{2}{c}{ Regression Statistics } \\
\hline Multiple R & 0,99985431 \\
\hline R Square & 0,99970864 \\
\hline Adjusted R Square & 0,999672221 \\
\hline Standard Error & 2,743378037 \\
\hline Observations & 10 \\
\hline
\end{tabular}

Tab. 1. Summary output

Multiple $\mathrm{R}$ represents the correlation ratio ( $\mathrm{R})$, whereby it measure the intensity of the relation between the solutions $\mathrm{pH}$ and the of electrode potential. $\mathrm{R}=$ 0.9998 shows that between $\mathrm{pH}$ solutions and the potential response of the electrode is a strong connection.

The coefficient of determination $\left(\mathrm{R}\right.$ square $=\mathrm{R}^{2}$ ) has the value 0.9997 , which means that the regression model explains $99.97 \%$ of the variation of sensor`s potential response. It is also computed the adjusted coefficient of determination, which is usually used in multiple regression. It is calculated the standard error, equal to 2.7433. If this value was zero, it could be said that all points are on the right side of the regression. 
\begin{tabular}{|ll|lll|} 
Coefficients Standard Error tstat & P.value & Lower 95\% & Upper $95 \%$ Lower $95,0 \%$ & Upper $95,0 \%$ \\
\hline
\end{tabular} \begin{tabular}{lllllllll}
\hline Intercept & 318,411458 & 2,061390702 & 154,46439 & $3,45197 \mathrm{E}-15$ & 313,6578824 & 323,165033 & 313,65778224 & 323,1650334
\end{tabular} $\begin{array}{lllllllll}\mathrm{pH}(\mathrm{x}) & -50,955832 & 0,307557844 & -165,67886 & 1,97072 \mathrm{E}-15 & -51,60506155 & -50,4660022 & -51,0650616 & -50,24600224\end{array}$ Tab. 2. Regression coefficients calculus

Tab. 2 represents regression model coefficients, intercept - constant term (318.4114) which is where the regression intersects the $\mathrm{y}$ axis (the value of $\mathrm{y}$ when $\mathrm{x}=$ 0 ), and coefficient $b$ is -50.9558 , which means that increasing the $\mathrm{pH}$ by one unit, the number $\mathrm{mV}$ 's drops with 50.9558 .

Hereunder we test the significance of these coefficients, with the ,t” test, because $\mathrm{t}_{\mathrm{b} 0}=154.4643$, and the threshold of significance P-value is 3.452 E-15<0.05 means that this coefficient is significant.

Regression equation is: $\mathrm{y}=50,956 \mathrm{x}+318.41$.

The model reflects the link between $\mathrm{pH}$ of the solutions and the voltage supplied by the sensor, validity of the model is tested using the "F" test (Fischer Dispersion analysis ANOVA), see Tab. 3.

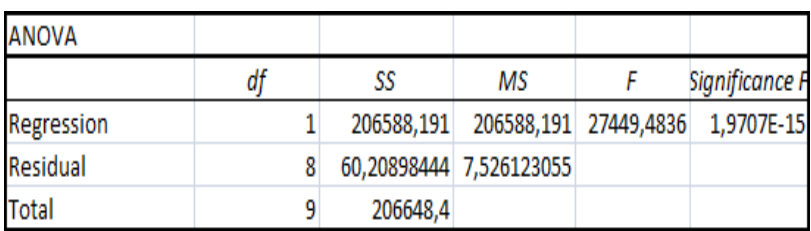

Tab. 3. ANOVA Tab

df - "the degrees of freedom"

$\mathrm{SS}$ - "the sum of squares"

MS - is the ANOVA expression of variance, or, "the mean squares"

$\mathrm{F}=\mathrm{MS}$ (factor) / MS (error) - is the ratio ANOVA

The ANOVA Tab. represents the calculus of three variances: the model explained, residual and total. With those it is calculated $F=27449.4836$. Significance $F$ (significance threshold) is $1.97072 \mathrm{E}-15$ (value less than 0.05), resulting that the built regression model is valid and can be used to analyze the dependence between those two variables.

\section{CONCLUSIONS}

The antimony sensor adapted to a laboratory installation used for the monitoring the soil, has a sTab. response to $\mathrm{pH}$ changes in aqueous solutions. Its potential has a linear relation with solutions $\mathrm{pH}$ (coefficient of determination $\mathrm{R}^{2}=0.9997$ ) and a slope of $50.95 \mathrm{mV} / \mathrm{pH}$.

Because the obtained results in terms of performance sensitive sensor were satisfying, studies will continue to reduce the dimension of the sensor and to improve its functional performance.

After studies and tests of the antimony sensor, we can say that the sensor can be successfully used in practice. It shows a linear and $\mathrm{sTab}$. response to $\mathrm{pH}$ changes in range 2-10. Its response time is relatively fast, and it was empirically determined in several series of tests. As a future goal, it follows the testing of this type of sensor on several soils, whether polluted or not, under either laboratory facilities or in open environments.

\section{ACKNOWLEDGEMENTS}

This paper was supported by the project "Progress and development through post-doctoral research and innovation in engineering and applied sciences - PRIDE - Contract no. POSDRU/89/1.5/S/57083", project cofunded from European Social Fund through Sectorial Operational Program Human Resources 2007-2013.

\section{REFERENCES}

[1] Nenițescu C.D., General Chemistry, Bucharest EDP, 1985

[2] Stoica O., Micle V., Study on glass and antimony sensors used for measuring $\mathrm{pH}$ during the bioremediation process of soil, Buletinul Institutului Politehnic din Iași, Stiința și Ingineria Materialelor, Tomul LVII(LXI), 2011, pp. 253-262

[3] Fraden J., Handbook of modern sensors, Physics, Designs and Applications,

Third

Edition,http://books.google.com/books/about/Handbook_of_mode rn_sensors.html?id=SB7glOc4VlAC

[4] Ha Y., Wang M., Capillary melt method for micro antimony oxide pH electrode, Electroanalysis 18, 2006, no. 11, pp. 1121 1125, http://www3.interscience.wiley.com/cgi in/fulltext/ 112638033/PDFSTART

[5] Stoica O., Micle V., Research regarding the adaptation of a metalic sensor from antimony, used for soils $\mathrm{pH}$ monitoring in the biological depollutions, Metalurgia International, 2011, vol. XVI no.2, pp. $16-20$

[6] Lurie I. I., Analitical chemistry, Technical Ed., Bucharest, 1970, pp. 231

[7] Anghelache C., Badea S.G., Capanu I., Wagner P., Theoretical and Economics Basis, Economical Ed., 2005

[8] Baghdady H. H., Sommer K., Improved construction of antimony micro-electrodes for measuring $\mathrm{pH}$-changes at the soil-root interface (rhizosphere), Plant Nutrition 1987, 10, 1231

[9] Schirrmann M, Gebbers R., Kramer E., Seidel J., Soil pH Mapping with an On-The-Go Sensor, Sensors, 2011, Vol. 11, pp. 573-598

[10] Stoica O., Micle V., Research regarding the adaptation of a metalic sensor from antimony, used for soils $\mathrm{pH}$ monitoring in the biological depollutions, Metalurgia International, 2011, vol. XVI no.2, pp. 16-20

[11] Sandru Mariana, Statistical methods of educational management optimisation, Matrix Rom Ed, Bucharest, 2011.

[12] CEO Water Mandate (2007) The CEO Water Mandate: An initiative by business leaders in partnership with the international community, UN Global Compact

[13] Costanza, R., Daly, H.E. (1992) Natural capital and sustainable development, Conservation Biology, 6: 37-46

[14] Falkenmark, M. (2003) Freshwater as shared between society and ecosystems: from divided approaches to integrated challenges, Philosophical Transaction of the Royal Society of London B 358(1440): 2037-2049 